\title{
O uso de plantas medicinais em infecções bucais: uma alternativa eficaz
}

\author{
The use of medicinal plants in oral infections: an effective alternative
}

El uso de plantas medicinales en infecciones bucales: una alternativa eficaz

Thallysson Jose Dourado de Sousa ${ }^{1 *}$, Larissa Kellen Oliveira Araujo ${ }^{1}$, Antônio Carlos Melo Lima Filho $^{1}$, Caroline Amélia Gonçalves ${ }^{1}$, Milena Sousa Freitas ${ }^{1}$, Michael Ranniery Garcia Ribeiro ${ }^{1}$, Júlio Evangelista de Lucena ${ }^{1}$, Arannadia Barbosa Silva ${ }^{1}$, Domingos Magno Santos Pereira1', Cristiane Santos Silva e Silva Figueiredo ${ }^{1}$.

\begin{abstract}
RESUMO
Objetivo: Descrever a eficácia das atividades medicinais encontradas em algumas espécies vegetais que podem ser utilizadas para o tratamento de infecções bucais. Revisão bibliográfica: $O$ uso de plantas para fins medicinais vem sendo utilizado como coadjuvante para o tratamento de patologias bucais desencadeadas a partir de infecções causadas por bactérias, vírus e fungos. Com base nos estudos, as plantas Camomila, Malva, Romã, Gengibre, possuem potencial farmacológico por desenvolver atividades antialérgica, antiinflamatória, ansiolítica, calmante, carminativa, cicatrizante, emoliente, imunoestimulante. Considerações finais: A partir dos estudos, conclui-se que as plantas estudadas podem atuar com potencial farmacológico no tratamento de infecções bucais, sendo de fácil acesso e baixo custo, quando comparado as drogas farmacológicas desenvolvidas na indústria farmacêutica. Além disso, as plantas acima relatadas possuem propriedades para a busca de novos estudos que irão contribuir nas ciências da saúde, especialmente na odontologia, devido as atividades que são desempenhadas pela ação farmacológica, diminuindo as infecções bucais.
\end{abstract}

Palavras-chave: Plantas medicinais, Infecções, Odontologia, Tratamento.

\begin{abstract}
Objective: Describe the effectiveness of medicinal activities found in some plant species that can be used to treat oral infections. Bibliographic review: The use of plants for medicinal purposes has been used as an adjunct to the treatment of oral pathologies triggered by infections caused by bacteria, virus and fungi. Based on the studies, the Camomile, Malva, Pomegranate, Ginger plants have pharmacological potential for developing antiallergic, anti-inflammatory, anxiolytic, soothing, carminative, healing, emollient, immunostimulant activities. Final considerations: From the studies, it is concluded that the studied plants can act with pharmacological potential in the treatment of oral infections, being easily accessible and low cost, when compared to the pharmacological drugs developed in the pharmaceutical industry. In addition, the plants reported above have properties for the search for new studies that will contribute to health sciences, especially in dentistry, due to the activities that are performed by the pharmacological action, reducing oral infections.
\end{abstract}

Keywords: Medicinal plants, Infections, Dentistry, Treatment.

\section{RESUMEN}

Objetivo: Describa la efectividad de las actividades medicinales que se encuentran en algunas especies de plantas que pueden usarse para tratar infecciones bucales. Revisión bibliográfica: El uso de plantas con fines medicinales se ha utilizado como coadyuvante en el tratamiento de patologías bucales desencadenadas por infecciones provocadas por bacterias, virus y hongos. Según los estudios, las plantas de manzanilla, malva, granada y jengibre tienen potencial farmacológico para desarrollar actividades antialérgicas, antiinflamatorias, ansiolíticas, calmantes, carminativas, cicatrizantes, emolientes e inmunoestimulantes. Consideraciones finales: De los estudios se concluye que las plantas estudiadas pueden actuar con potencial farmacológico en el tratamiento de infecciones bucales, siendo de fácil acceso y bajo costo, en comparación con los fármacos farmacológicos desarrollados en la industria farmacéutica. Además, las plantas reportadas anteriormente tienen propiedades para la búsqueda de nuevos estudios que contribuyan a las ciencias de la salud, especialmente en odontología, debido a las actividades que se realizan por acción farmacológica, reduciendo las infecciones bucales.

Palabras clave: Plantas medicinales, Infecciones, Odontología, Tratamiento.

1 Universidade Ceuma (UNICEUMA), Imperatriz - MA. *E-mail: br526thallyssondourado@gmail.com 


\section{INTRODUÇÃO}

A boca é um meio de entrada não só de alimentos e bebidas, mas também de doenças que podem afetar a saúde do indivíduo e até mesmo ocasionar o óbito. Por isso é fundamental manter a saúde bucal para ter o bom funcionamento do organismo como um todo. As infecções bucais desenvolvidas por bactérias, vírus e fungos, podem se tornar muito perigosas se não tratadas, podendo chegar na corrente sanguínea trazendo comprometimento ao paciente. Um exemplo de infecções bucais é a cárie, ocasionada por alguns tipos de bactérias que quando não tratada, pode acessar o canal do dente e posteriormente acessar outras regiões do corpo, gerando complicações generalizadas (ALELUIA C de M, et al., 2015).

Outro exemplo é a candidíase bucal ocasionado pelo fungo Candida albicans na boca, que se dá a partir de saliências na língua ou na bochecha, com placas que causam ardor de coloração esbranquiçada na boca, língua e garganta, podendo quando generalizada, atingir o esôfago, causando dor e dificuldade para engolir. Tem-se ainda a herpes bucal, causada pelo vírus herpes simplex, que é responsável por feridas que aparecem na boca e causando sintomas desagradáveis. Além dessas infecções citadas, existe outras patologias que podem estar associadas a infecções bacterianas, virais e fúngicas na cavidade bucal (ALELUIA C de M, et al., 2015).

Atualmente a ciência vem buscando diversos tratamentos para o cuidado das patologias bucais desencadeadas a partir de infecções por bactérias, vírus e fungos. O uso de plantas medicinais, por exemplo, já ocorre há milhares de anos, sendo que nossos antepassados costumavam realizar esse tipo de prática para curar diversas enfermidades. O primeiro relato manuscrito foi intitulado Papiro de Ebers, datado aproximadamente de 1550 a.C. no antigo Egito. Desde então, a utilização de plantas medicinais no tratamento de patologias, apresenta-se como uma alternativa terapêutica eficaz (FRANCISCO KMS, 2010).

Nos dias de hoje o uso de plantas medicinais ainda é muito comum, estima-se que aproximadamente $80 \%$ da população mundial já tenha utilizado alguma planta para aliviar sintomas de alguma enfermidade. A partir de diversas indagações sobre propriedades medicinais contidas nas plantas, surgiu-se inúmeros estudos para pesquisar os constituintes das plantas utilizadas para fins medicamentosos (FRANCISCO KMS, 2010).

Segundo Alves PM, et al. (2009) as plantas medicinais são constituídas de inúmeras propriedades, princípios ativos e substâncias que permitem a cura ou tratamento de doenças, as que envolve a cavidade bucal. Tal efeito se dá devido à ação farmacológica dos óleos essenciais, que tem presentes substâncias como flavonoides, alcaloides, taninos, etc. Tais substâncias desempenham funções cicatrizantes, bactericidas, analgésicas, relaxantes, anti-inflamatórias, antimicrobianas, expectorantes, analgésicas, dentre outras. As plantas medicinais estão bem presentes na contemporaneidade constituindo produtos na indústria alimentícia, de bebidas, cosméticos e principalmente na indústria farmacêutica. Utiliza-se as plantas medicinais através de chás, infusões, óleos essenciais, garrafadas e entre outras formas.

$\mathrm{Na}$ odontologia as plantas medicinais são empregadas principalmente pela atividade antimicrobiana, bactericida e cicatrizante. Isso ocorre devido a região bucal ser "porta de entrada" para microrganismos tornando-a mais propensa ao desenvolvimento e proliferação de patógenos que atuam na região. Diversos estudos possibilitam o conhecimento sobre a eficácia das plantas medicinais empregadas na odontologia, um exemplo é o estudo de Gasparetto JC, et al. (2012), que concluiu que as plantas medicinais atuam como antioxidantes, antiacne, antialérgica, além de possuir ação para aliviar ferimentos na região da boca. Já o estudo de Razavi SM, et al. (2011), buscou a mesma finalidade em demonstrar a eficácia das plantas medicinais e concluiu que elas possuem efeitos antibacteriano, atividade citotóxica, atuam como gente antiproliferativo, reduz o cancro e atuam como agente antisséptico na região bucal.

Diante o potencial farmacológico das plantas medicinais reconhecido no meio científico, as indústrias farmacêuticas passaram a fabricar medicamentos com atividades e propriedades advindas das plantas medicinais que foram comprovadas cientificamente, trazendo segurança, praticidade e confiabilidade dos resultados no consumo destes medicamentos. Estima-se que $25 \%$ dos medicamentos atuais são desenvolvidos, direta ou indiretamente, por meio de recursos vegetais, que foram validados, mediante experimentos realizados pela comunidade científica em face a da industrialização e modernização dos medicamentos (MONTEIRO MHDA, et al., 2015). 
Mesmo diante do crescimento da indústria farmacêutica para a elaboração de fármacos com potencial farmacológico específico, boa parte da população mundial não tem acesso a estes produtos devido ao custo e acesso ao medicamento. Diante disso, a população em geral opta pelo uso de plantas medicinais como alternativa terapêutica em função de uma tradicionalidade de nossos ancestrais e uma relação de confiança com os recursos vegetais com potencial farmacológico (MING LC, et al. 2012).

A utilização de práticas terapêuticas provindas de plantas medicinais tornou-se oficialmente reconhecida apenas no final do ano 1970, com a realização da Conferência Internacional sobre Atenção Primária em Saúde em Alma-Ata, na Suíça, promovida pela Organização Mundial da Saúde (OMS) e o Fundo das Nações Unidas para a Infância (UNICEF). A partir daí tornou-se oficial na esfera mundial o reconhecimento e importância do uso das plantas com fins medicinais para o meio científico e popular (MING LC, et al. 2012).

Tendo em vista a necessidade de terapias que atendam a saúde do indivíduo, em especial a saúde bucal, este estudo tem como objetivo descrever a eficácia das atividades medicinais encontradas em algumas espécies vegetais que podem ser utilizadas para o tratamento de infecções bucais. Além disso, contribuir com o conhecimento a fim de melhorar a qualidade de vida, a partir do uso de plantas medicinais.

\section{REVISÃO DE BIBLIOGRÁFICA}

O uso de plantas medicinais, assim como em outras áreas, vem se desenvolvendo na odontologia, mediante propriedades naturais com potencial terapêutico. Atualmente a odontologia, vem explorado diversas plantas com potencial farmacológico para auxiliar o tratamento de infecções bucais (infecções bacterianas, fúngicas e inflamações). São várias espécies vegetais que podem apresentar eficácia na aplicação clínica em patologias que acometem a cavidade bucal, auxiliando o tratamento de várias doenças bucais é possível destacar a contribuição para o tratamento destas afeç̧ões (JUNIOR JI e MONTEIRO AB, 2020).

$\mathrm{Na}$ odontologia, a utilização de plantas medicinais para tratar doenças bucais ou para tratar doenças sistêmicas com manifestações bucais ainda é pouco explorada. Apesar disso, nos últimos anos estudos relacionados a área cresceu significantemente em comparação ao aumento pela busca por produtos de maior atividade farmacológica, com menor toxicidade, e biocompatíveis, além de custos mais acessíveis à população (MACHADO AC e OLIVEIRA RC, 2014).

A realização de pesquisas sobre o assunto mostra que o potencial farmacológico das plantas pode ser utilizado para inibir o crescimento bacteriano e a aderência nas superfícies dentais. Por exemplo, espécies como Camomila, Malva, Romã e Gengibre são indicadas nos casos de gengivite, doença periodontal, úlceras traumáticas, candidíase, herpes labial, mucosite e inflamação. Essas plantas vêm cientificamente apresentando ação bactericida e bacteriostática sobre bactérias Gram-positivas e Gram-negativas constituintes do biofilme dental (MACHADO AC e OLIVEIRA RC, 2014).

A seguir será descrito quatro espécies de plantas com propriedades antimicrobianas, antioxidantes, antiinflamatórias e cicatrizantes que atuam sobre eficácias em patologias bucais causadas por inflamações e/ou infecções bacterianas, são elas: Camomila, Malva, Romã, Gengibre.

\section{Camomila (Matricaria Chamomilla Linnaeus)}

Matricaria Chamomilla Linnaeus (MCL) é uma planta herbácea da família Asteraceae, que apresenta caule ereto, glabro e ramificado, chegando a alcançar cerca de 30 a $50 \mathrm{~cm}$ de altura. Sendo nativa de clima mediterrâneo, a MCL chega a se desenvolver em regiões no sul da Europa, na América do Norte, América Central e América do Sul. Também conhecida como Camomila, Camomila-alemã, Camomila-húngara e Matricaria, é comercializada devido seu aspecto singelo, seu perfume delicado e doce, é comumente utilizada na produção de produtos de limpeza, cosméticos e produtos culinários (SINGH O, et al., 2011).

Além disso, também é utilizada para fins terapêuticos/medicinais devido a propriedades fitoquímicas presentes na sua constituição química, como matricina, flavonóides (apigenina e quercitina), resinas, cumarinas (dioxicumarina, umbeliferona e herniarina), taninos, além do óleo essencial, constituído por alfa- 
bisabolol e camazuleno. Tais constituintes fitoquímicos desempenham atividades antiespasmódica, digestiva, antisséptica, antialérgica, anti-inflamatória, ansiolítica, calmante, carminativa, cicatrizante, emoliente e imunoestimulante (SINGH O, et al., 2011).

Em um estudo in vitro realizado por Albuquerque ACL, et al. (2010) o autor observou o potencial antimicrobiano do efeito da camomila em linhagens bacterianas padronizadas. As linhagens utilizadas foram Streptococcus mutans (ATCC25175), Streptococcus sanguinis (ATCC10557) e Lactobacillus casei (ATCC7469) que são microrganismos presentes na formação do biofilme dental. O estudo se desenvolveu a partir da Determinação da Concentração Inibitória Mínima de Aderência (CIMA) do Extrato Hidroalcóolico da Matricaria recutita Linnaeus. Para a determinação da CIMA foram utilizados tubos de hemólise na presença de sacarose a $5 \%$ e de uma solução diluída do extrato bruto isolado da camomila até uma diluição de 1:1024 (10 diluições).

O estudo visou simular a aderência dos microrganismos ao elemento dental permitindo a observação visual, após coloração com fucsina. A CIMA apresentou a menor concentração do extrato, em meio com sacarose, impedindo a aderência ao tubo de vidro de hemólise. Os resultados dos estudos apresentaram dados comparativos da CIMA do extrato da Matricaria recutita Linn. e Clorexidina $0,12 \%$ (grupo controle) sobre as linhagens bacterianas citadas acima. O extrato da Matricaria recutita Linn apresentou 1:4 CIMA sobre a $S$. mutans e 1:4 CIMA sobre a $L$. casei, ambas comparadas ao grupo controle apresentaram a CIMA de 1:16. Já a Matricaria recutita Linn apresentou 1:8 CIMA sobre a $S$. sanguinis e quando comparado ao grupo controle, apresentou a CIMA de 1:16 (ALBUQUERQUE ACL, et al., 2010).

Assim, o estudo mostra a capacidade da concentração mínima inibitória da Matricaria recutita Linn sobre as linhagens bacterianas $S$. mutans, L. casei e $S$. sanguinis. Dentre as três linhagens bacterianas estudas, observou-se que a CIMA da Matricaria recutita Linn quando aplicada sobre S. sanguinis desenvolveu melhor CIMA, devido a melhor aderência ao elemento dental, demonstrando que a ação da camomila sobre a inibição do biofilme dental e a inibição da aderência de microrganismo na região bucal (ALBUQUERQUE ACL, et al., 2010).

Em outro estudo foi avaliado o efeito da MCL no tratamento de úlceras orais em ratos. Para realização do estudo foram utilizados 36 ratos, que foram divididos em dois grupos: 1) animais tratados e 2) animais não tratados (grupo controle). Em todos os animais foram feitos um ferimento de $5 \mathrm{~mm}$ na língua. Nos animais do grupo tratado foi administrado uma pomada na concentração de $0,04 \mathrm{~mL} /$ dia de extrato de camomila, enquanto os animais do grupo controle não foram tratados. Os animais tratados obtiveram melhor cicatrização no processo de reparo tecidual em comparação com grupo controle (DUARTE CME, 2011).

Diante o estudo apresentado, pode-se concluir que a camomila é uma importante alternativa terapêutica para auxiliar nas infecções bucais desenvolvidas por algumas bactérias, devido ao potencial antimicrobiano, anti-inflamatório e possivelmente antioxidante. Por isso sugere-se que a MCL pode ser um composto promissor para auxiliar no tratamento de infecções bucais provocadas por microrganismos.

\section{Malva (Malva sylvestris)}

Malva sylvestris (MS) é uma planta herbácea da família Malváceas, que apresenta galhos elevados, pilosos e ramificados, chegando a alcançar 1 metro de altura. É nativa de clima subtropical e se desenvolve em regiões de quase toda a Europa, África e norte da Ásia. Também conhecida como Malva, Gerâneoaromático, Malva-rosa e Rosa-chinesa, é comercializada devido seu aroma suave e doce, e é comumente utilizada na produção de cosméticos, produtos alimentícios, farmacológicos e culinários (ECKER ACL, et al., 2015).

Além disso, também é utilizada para fins terapêuticos/medicinais devido constituintes fitoterápicos presentes na sua composição, como ácido cumarínico, clorogênico e cafeico, flavonóides, taninos, derivados antraquinônicos, mucilagens, carotenos e o seu óleo essencial, constituído de ácidos oléico, palmítico e esteárico, propriedades que desempenham atividades anti-inflamatória, digestiva, expectorante, hipoglicemiante, laxante suave, além de imuno-estimulante (ECKER ACL, et al., 2015). 
Segundo Gomes MS, et al. (2020) a Malva sylvestris tem potencial farmacológico como anti-inflamatório e antimicrobiano, devido à presença de mucilagens, taninos, óleos essenciais, glicolipídios e flavonoides. Além disso, apresenta redução ao crescimento das bactérias do biofilme dental, por atuar na inibição do crescimento bacteriano.

Moreira MJS, et al. (2012) avaliou a atividade antibacteriana de uma formulação de antisséptico bucal composta de guinosol, tintura de malva e tirotricina contra os microrganismos Lactobacillus spp e Streptococcus mutans, bactérias encontradas geralmente na cavidade bucal. Na formulação utilizou-se quinosol $1 \mathrm{mg} / \mathrm{mL}$, tintura de malva $0,005 \mathrm{mg} / \mathrm{mL}$ e tirotricina $0,1 \mathrm{mg} / \mathrm{mL}$. Como controle positivo utilizou-se clorexidina a $0,12 \%$. Sobre o Streptococcus mutans e Lactobacillus spp, a malva apresentou os resultados (em mediana) de $23,47 \mathrm{~mm}$ e $8,61 \mathrm{~mm}$ respectivamente, mostrando que a Malva apresenta atividade antimicrobiana superior a Streptococcus mutans, Lactobacillus spp quando comparada as demais substâncias.

Diante o estudo apresentado, observa-se o potencial antimicrobiano dos componentes da malva contra Streptococcus mutans, Lactobacillus spp, podendo ser um importante agente antibacteriano para o tratamento em infecções bucais provocadas por estes microrganismos.

A atividade antimicrobiana dos constituintes de antisséptico bucal que se compõe de compostos como guinosol, tintura de malva e tirotricina que agem contra infecções provocadas por Lactobacillus spp e Streptococcus mutans, bactérias encontradas geralmente na cavidade bucal. Utilizou-se a concentração de quinosol $1 \mathrm{mg} / \mathrm{mL}$; tintura de malva $0,005 \mathrm{mg} / \mathrm{mL}$; tirotricina $0,1 \mathrm{mg} / \mathrm{mL}$ e como controle positivo utilizou uma solução de clorexidina $0,12 \%$.

\section{Romã (Punica Granatum)}

Punica Granatum (PG) é uma planta arbustiva da família Punicaceae, que apresenta galhos elevados repletos de folhagens diversas com cores, incluindo branco, rosa e roxo, chegando a alcançar entre 2 a 5 metros de altura. Os seus frutos apresentam casca dura em formato arredondado de cor avermelhada, que quando maduros expõem as suas sementes para fora do fruto. É nativa do clima árido subtropical e tropical, em regiões como Irã e Ásia, mas se desenvolve em quase todas as regiões do Brasil (SOUSA NCF, et al., 2018).

Também conhecida como Romãzeira e Romeira, é comercializada devido seu potencial farmacológico presente nos frutos, folhas e sementes e é comumente utilizada na produção de cosméticos e produtos alimentícios. Além disso, também é utilizada para fins terapêuticos/medicinais devido os constituintes presentes na sua composição, como celulose, lignina, flavonóides, cálcio, ferro, manganês, vitaminas B1, B2 e $\mathrm{C}$ o seu óleo essencial, constituído de compostos fenólicos, que desempenham atividades como o antiinflamatória, antimicrobiana e antioxidante (SOUSA NCF, et al., 2018).

Em um estudo in vitro realizado por Argenta JA, et al. (2012) foi avaliado o efeito inibitório de extratos de plantas sob Streptococcus mutans. Foram elaborados 3 grupos de dentifrícios, designados como dentifrício A com $3 \%$ de extrato de romã, dentifrício $\mathrm{B}$, com $1 \%$ de extrato de romã e dentifrício $\mathrm{C}$, sem adição de extrato de romã (grupo controle). O estudo também avaliou as médias dos índices de biofilme dentário (\%) em diferentes intervalos de tempo para os grupos dentifrício $A$, dentifrício $B$ e dentifrício $C$, que tiveram os valores médios obtidos para cada grupo, avaliados individualmente entre o $1^{\circ}$ e $8^{\circ}$ dias, o dentifrício $A$ apresentou Média dos Halos de Inibição (mm) 46,03 ( $\pm 31,92)$ e 25,28 ( $\pm 16,94)$, respectivamente.

Já o dentifrício B apresentou as médias $51,71( \pm 31,08) 35,28( \pm 18,56)$, respectivamente e quando comparado ao dentifrício A e dentifrício $B$, o grupo controle (dentifrício C) apresentou 45,57 $( \pm 30,37) 40,91$ $( \pm 20,43)$, mostrando que a média quando comparada ao $1^{\circ}$ e $8^{\circ}$ dia do dentifrício $A$, teve o percentual de redução de $45,07 \%$, já o dentifrício $B$ teve o percentual de redução $31,77 \%$ e o dentifrício $C$ teve o percentual $10,22 \%$.

Ao fim do estudo foi possível apontar que os resultados obtidos mostraram que a Punica Granatum apresentou atividade in vitro sob Streptococcus mutans, sendo que o dentifrício grupo A apresentou o melhor 
percentual de redução sob o Streptococcus mutans. Deste modo, o presente estudo demonstrou a eficácia do extrato de romã sobre a bactéria Streptococcus mutans quando comparado ao grupo controle, assim, sugere-se que o extrato de romã pode ser eficaz para atuar inibindo o crescimento de Streptococcus mutans em infecções bucais.

Em seu estudo Gomes MS, et al. (2020) mostrou que o extrato hidroalcóolico da casca da romã possui potencial inibitório na formação de biofilme dentário nas concentrações de 1:512, 1:256, 1:128, 1:256 e 1:1.024 sobre Streptococcus mitis, Streptococcus mutans, Streptococcus sanguis, Streptococcus sobrinus e Lactobacillus casei respectivamente, quando comparados ao grupo controle. No mesmo estudo observouse a eficácia do extrato de $P$. granatum em atividade antiviral, inibindo vírus como Herpes Simples e Poliovírus, que podem estar presentes na região bucal. Assim, o presente estudo apresenta o potencial farmacológico e a eficácia do extrato hidroalcóolico da casca da romã sobre a inibição da formação de biofilme dentário. (PEREIRA JV, et al., 2006).

A romã possui diversos constituintes fitoquímicos com propriedades medicinais, um deles é o tanino, que pode auxiliar no tratamento da periodontite, pelo seu potencial antimicrobiano, antioxidante e cicatrizante. Assim, tornando-se um composto promissor para a fitomedicina aplicada na odontologia.

\section{Gengibre (Zingiber Officinale)}

Zingiber officinale (ZO) é uma planta herbácea da família Zingiberaceae, que apresenta hastes longas, de onde se desenrolam folhas relativamente estreitas e compridas, chegando a alcançar até 1,5 metro de altura. Sendo nativa de clima subtropical como Ásia, llha da Java, China e chegando a se desenvolver em regiões do Brasil. Também conhecida como gengibre-de-jamaica, gengibre-africano, gengibre-de-cochim e marangatiá é comercializada devido seu peculiar sabor e aroma, sendo comumente utilizada na produção de produtos alimentícios, cosméticos e produtos culinários (PALMEIRA PTSS, et al., 2019).

Além disso, também é utilizada para fins terapêuticos/medicinais devido à presença de compostos ativos na sua composição, como flavonóides, vitaminas ( $B 1, B 2, B 3, C, E, K$ e A), magnésio, fósforo, cálcio, sódio, ferro, zinco, potássio, cromo, manganês, silício, proteínas, incluindo os aminoácidos asparagina e ácido glutâmico, além do óleo essencial que tem em sua constituição componentes fitoquímicos como os fenóis. Esses componentes ativos e compostos fitoquímicos desempenham atividades como energéticos, antiinflamatórios, analgésicos, diuréticos e facilita o processo de digestão (PALMEIRA PTSS, et al., 2019).

Segundo Avcioglu NH, et al. (2016) o efeito antibiofilme do óleo essencial de Zingiber officinale pode ser testado em infecções com a bactéria Klebsiella sp. O estudo avaliou os efeitos antibiofilme de óleo essencial de Zingiber officinale sobre a formação de biofilme de bactérias $K$. ornithinolytica, K. oxytoca e K. terrigena. Os resultados apresentaram diminuição em todas as espécies da bactéria que formaram biofilme quando diluídas na concentração de $10^{-1} \mathrm{UFC} / \mathrm{mL}$ mostrando que o gengibre tem ação direta na diminuição da formação do biofilme. Portanto, considera-se que o óleo essencial pode ser usado como alternativa terapêutica para auxiliar no tratamento de infecções bucais causadas pelos microrganismos destacados.

Chakotiya AS, et al. (2017) avaliaram a eficácia da Z. officinale em isolados clínicos de Pseudomonas aeruginosa que se mostraram resistentes a diversos antibióticos. No presente estudo, avaliou-se o efeito antibacteriano de Zingiber officinale contra cepa multirresistente de $P$. aeruginosa. Como resultados o estudo observou que houve declínio na formação das UFC's (Unidades Formadoras de Colônia) em 12 h de tratamento. Avaliou-se ainda por citometria de fluxo, utilizando o lodeto de Propídio como revelador, a integridade da membrana do patógeno, havendo desintegração bacteriana de $86,9 \pm 2,08 \%$ de células. A capacidade de inibição da formação de biofilme foi encontrada na faixa de $68,13 \pm 4,11 \%$ a 84,86 $\pm 2,02 \%$. Assim, mostrando que $Z$. officinale é eficaz em infecções de isolados clínicos de $P$. aeruginosa multirresistente ao afetar a integridade da membrana plasmática e inibir a formação de biofilme.

Portanto, diante os estudos mostrados, demostra-se que $Z$. officinale apresenta características antibacterianas contra bactérias Gram-positivas e Gram-negativas que podem causar infecções na cavidade bucal com formação de biofilme. 


\section{CONSIDERAÇÕES FINAIS}

As plantas estudadas podem atuar com potencial farmacológico no tratamento de infecções bucais, sendo de fácil acesso e baixo custo, quando comparado as drogas farmacológicas desenvolvidas na indústria farmacêutica. Além disso, as plantas acima relatadas possuem alta relevância para a busca de novos estudos para contribuir nas ciências da saúde, especialmente na odontologia, devido as atividades que são desempenhadas pela ação farmacológica, como anti-inflamatória, antioxidante, antibacteriana, dentre outras. Diante disso, sugere-se que a Camomila, Malva, Romã, Gengibre são plantas promissoras para contribuir medicinalmente na odontologia, seja com o uso do óleo essencial ou extrato, a partir da inibição e/ou diminuição da formação de biofilme dental, e do crescimento de microrganismos, além de atuar como inflamações.

\section{REFERÊNCIAS}

1. ALBUQUERQUE ACL, et al. Efeito antimicrobiano do extrato da Matricaria recutita Linn. (camomila) sobre microrganismos do biofilme dental. Pesquisa. Brasileira. Odontopediatria Clín. Integr. 2010; 10(3): 451-55.

2. ALVES PM, et al. Atividade antimicrobiana, antiaderente e antifúngica in vitro de plantas medicinais brasileiras sobre microrganismos do biofilme dental e cepas do gênero Candida. Rev. Soc. Bras. Med.Trop, 2009; 42(2): 222-224.

3. ARGENTA JA, et al. Efeito do extrato de romã (Punica granatum) sobre bactérias cariogênicas: estudo in vitro e in vivo. Arquivos em Odontologia, 2012; 48(4): 218-226.

4. AVCIOGLU NH, et al. Antibiofilm effects of citrus limonum and Zingiber officinale oils on biofilm formation of Klebsiella ornithinolytica, Klebsiella oxytoca and Klebsiella terrigena species. Afr J Tradit Complement Altern Med. 2016; 13(6): 61-67.

5. CHAKOTIYA AS, et al. Zingiber officinale: Its antibacterial activity on Pseudomonas aeruginosa and mode of action evaluated by flow cytometry. Microbial Pathogenesi, 2017; 254-260.

6. ALELUIA CM, et al. Fitoterápicos na odontologia. Rev. Odontol. Univ. Cid. São Paulo 2015; 27(2): 126-34.

7. ECKER ACL, et al. Efeitos benéficos e maléficos da malva sylvestris. Journal of Oral Investigations, 2016; 4(1): $39-43$.

8. FRANCISCO KMS. Fitoterapia: uma opção para o tratamento odontológico. Rev saúde 2010; 4(1): 18-24.

9. GRANDIS RA, et al. Avaliação da Atividade Antibacteriana do Gengibre (Zingiber officinale Roscoe) e do Maracujá Amarelo (Passiflora edulis Sims). Rev Ciênc Farm Básica Apl., 2015; 36(1): 77-82.

10. GASPARETTO JC, et al. Ethnobotanical and scientific aspects of Malva sylvestris L.: a millennial herbal medicine. Journal of Pharmacy and Pharmacology, 2012; 64(2): 172-189.

11. GOMES MS, et al. Uso de plantas medicinais na odontologia: uma revisão integrativa. Revista de Ciências da Saúde Nova Esperança, 2020; 18(2): 118-126.

12. DUARTE CME, et al. Effects of Chamomilla recutita (L.) on oral wound healing in rats. Med Oral Patol Oral Cir Bucal, 2011; 1(16):6; e716-21.

13. JUNIOR JI, MONTEIRO AB. Plantas medicinais e fitoterápicos úteis na odontologia clínica: uma revisão medicinal. Revista da Faculdade de Odontologia da UFBA, 2020; 50(1): 47-56.

14. MACHADO AC, OLIVEIRA RC. Medicamentos Fitoterápicos na odontologia: evidências e perspectivas sobre o uso da aroeira-do-sertão (Myracrodruon urundeuva Allemão). Revista Brasileira de Plantas Medicinais, 2014; 16(2): 283289.

15. MING LC, et al. Pesquisas agronômicas das plantas medicinais da Mata Atlântica regulamentadas pela ANVISA. Revista Brasileira de Plantas Medicinais, 2012; 14(SPE): 131-137.

16. MONTEIRO MHDA, et al. Fitoterapia na odontologia: levantamento dos principais produtos de origem vegetal para saúde bucal. Rev Fitos, 2015; 9(4): 265-68.

17. MOREIRA MJS, et al. Avaliação in vitro da atividade antimicrobiana dos componentes de um enxaguatório bucal contendo malva. Revista Pesquisa Brasileira em Odontopediatria e Clínica Integrada, 2012; 12(4): 505-509.

18. PALMEIRA PTSS, et al. O uso do gengibre (zingiber officinale) em odontologia: propriedades e aplicações terapêuticas. Brazilian Journal of Surgery and Clinical Research - BJSCR, 2019; 27(2): 110-115.

19. PEREIRA JV, et al. Efeito antibacteriano e antiaderente in vitro do extrato da Punica granatum Linn. sobre microrganismos do biofilme dental. Revista Brasileira de Farmacognosia, 2006; 16(1): 88-93.

20. RAZAVI SM, et al. Bioactivity of Malva Sylvestris L., a Medicinal Plant from Iran. Iran J Basic Med Sci. 2011; 14(6): 574-9.

21. SINGH O, et al. Chamomile (Matricaria chamomilla L.): an overview. Pharmacognosy reviews, $2011 ; 5(9): 82$.

22. SOUSA NCF, et al. Propriedades farmacológicas de Punica granatum L (romã): uma revisão de literatura. Revista Ceuma Perspectivas, 2018; 31(1): 57-67. 